\title{
Deep Brain Stimulation for Tourette Syndrome: Target Selection
}

\author{
Ashwin Viswanathan $^{\mathrm{a}} \quad$ Joohi Jimenez-Shahed $^{\mathrm{b}}$ José Fidel Baizabal Carvallo ${ }^{\mathrm{b}}$ \\ Joseph Jankovic ${ }^{b}$ \\ a Department of Neurosurgery, and b Parkinson's Disease Center and Movement Disorders Clinic, Department of \\ Neurology, Baylor College of Medicine, Houston, Tex., USA
}

\section{Key Words}

Tourette syndrome $\cdot$ Tics $\cdot$ Deep-brain stimulation

\begin{abstract}
Background/Aims: Tourette syndrome (TS) is a complex neurological disorder manifested chiefly by motor and phonic tics and a variety of behavioral comorbidities, including attention disorder, obsessive-compulsive disorder and impulse control problems. Surgical treatment is increasingly considered when tics become troublesome or even disabling or self-injurious despite optimal medical therapy. In this review, we describe the surgical techniques, stimulation parameters, outcomes of deep brain stimulation (DBS) in TS, and critically review target choices. Methods: A search of the PubMed database was performed to identify all articles discussing DBS and TS. 'Tourette' and 'Stimulation' were used as MeSH headings. Results: Since the first report of thalamic DBS for TS in 1999, follow-up on less than 100 patients has been reported in the literature. Reported targets for DBS include the thalamic centromedian nucleus and substantia periventricularis, posteroventral globus pallidus internus, ventromedial globus pallidus internus, globus pallidus externus, anterior limb of the internal capsule and nucleus accumbens. Conclusions: Determination of the optimal surgical target will require a multicenter, randomized trial, and an expanded understanding of the neurobiology of TS.
\end{abstract}

Copyright $\odot 2012$ S. Karger AG, Basel

\section{KARGER}

Fax +4161306 1234

E-Mail karger@karger.ch

www.karger.com (c) 2012 S. Karger AG, Basel

$1011-6125 / 12 / 0904-0213 \$ 38.00 / 0$

Accessible online at:

www.karger.com/sfn

\section{Introduction}

Tourette syndrome (TS) is a neurological and neurobehavioral disorder characterized by a waxing and waning course and a varied spectrum of comorbidities. The hallmark of TS is tics, which are brief, involuntary movements (motor tics) or sounds (phonic tics) [1]. TS usually presents with tics and behavioral disorders including attention deficit hyperactivity disorder and obsessive-compulsive disorder (OCD) in childhood, but the symptoms may persist into adulthood [2]. Tics are often preceded by a premonitory sensory phenomenon or an urge and are relieved by the execution of the movement or sound [3]. Since the discovery in the 1960s that neuroleptic drugs can lead to clinical improvement of TS, there has been a gradual shift from the notion that TS is a rare neuropsychiatric disorder to our current concept of TS as a relatively common, genetic, neurobiological disorder, probably resulting from dysfunction of the basal gangliacortical circuitry [4]. Despite advances in behavioral therapies and medical management, a subset of patients with TS exists in whom conventional treatment strategies do not lead to clinical improvement [5]. If the symptoms markedly interfere with daily activities or are associated with a self-injurious behavior (so-called 'malignant TS') [6], surgical intervention may need to be considered. The primary aim of this review is to provide a background

Assist. Prof. Ashwin Viswanathan, MD

Department of Neurosurgery, Baylor College of Medicine

1709 Dryden, Suite 750

Houston, TX 77030 (USA)

Tel. +1 713798 4696, E-Mail ashwinv@bcm.edu 
and rationale for targeting various structures in surgical treatment of TS and to summarize the published experience with DBS in TS.

\section{Methods}

A search of the PubMed database was performed to identify all articles discussing DBS and TS. 'Tourette' and 'Stimulation' were used as MeSH headings. Only articles written in English were reviewed. Twenty-seven articles were identified that provided surgical technique and clinical outcome data for patients treated with DBS for TS. When a single center had provided more than one report of their results, the longest follow-up was used for the analysis of outcomes. Care was taken to report the data of a given patient only once.

\section{Background}

Basal-ganglia circuits are segregated into parallel thalamocortical loops serving sensorimotor, oculomotor, limbic and associative functions $[3,7,8]$. The striatum and the subthalamic nucleus serve as the main inputs to the basal ganglia, and the globus pallidus pars interna (GPi) and the substantia nigra pars reticulata (SNpr) serve as the main output nuclei $[3,9,10]$. One leading hypothesis for the pathogenesis of TS involves the activation of aberrant groups of striatal neurons with inhibitory projections to the GPi and the SNpr. This in turn disinhibits thalamocortical projections involved in a specific unwanted motor pattern, leading to a tic $[3,11]$.

The centromedian and parafascicular nuclei (CM-Pf complex) receive input from the parallel motor, associative and limbic basal ganglia circuits [12]. These nuclei are part of the posterior laminar nuclei of the thalamus [13], and have been historically classified as part of the ascending reticulo-thalamo-cortical activating system [14]. However, the CM-Pf complex also participates in important thalamostriatal projections which can activate conditional responses modulated by the nigrostriatal dopaminergic system [15].

Projections from the CM nucleus include the pallidum and subthalamic nucleus, while the Pf nucleus projects to the nucleus accumbens (fig. 1) [12]. Primate studies support that sensorimotor circuits link the medial two-thirds of the CM nucleus and the caudal GPi, and limbic circuits link the rostral one-third of the Pf nucleus with the ventral striatum and the rostromedial pole of the GPi. The associative circuits connect the caudal two-thirds of the Pf nucleus with the caudate nucleus and substantia nigra

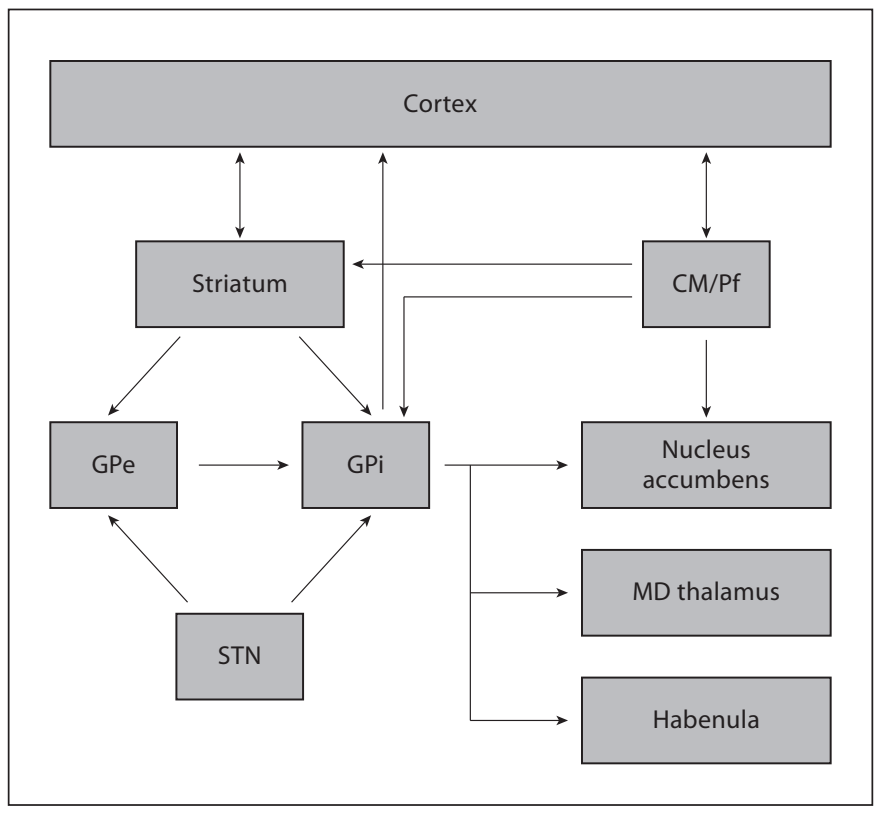

Fig. 1. Functional neuroanatomy of basal-ganglia circuitry relevant to the surgical treatment of TS. GPe = Globus pallidus externus; STN = subthalamic nucleus; $\mathrm{MD}$ thalamus = mediodorsal thalamus.

pars reticulata [16]. It is hypothesized that the interactions between limbic and sensorimotor circuitry can influence the motor and behavioral manifestations in TS [17].

The evidence supporting the role of basal-gangliathalamocortical circuits in the generation of tics and obsessive-compulsive behaviors has led to stereotactic targeting of these structures with the hopes of therapeutic efficacy. Since the 1960s, ablative techniques including frontal leukotomy, thalamotomy, dentatotomy, cingulotomy, and others have been applied in the surgical treatment of TS. Excellent, comprehensive reviews exist of these ablative techniques [18-20].

Ablative techniques targeting the interlaminar nuclei and the median part of the thalamus were introduced by Hassler and Dieckmann [21] in 1965. The authors used a stereotactic probe to stimulate and create multiple lesions within the median nucleus of the thalamus, the rostral interlaminar nucleus, and the ventro-oralis anterior nucleus of the thalamus. In 1970, Hassler and Dieckmann [22] reported 3 patients with TS in whom this technique was used bilaterally, and reported improvement of between 70 and $100 \%$ following coagulation. Hassler and Dieckmann ultimately updated their series to include 15 patients with TS. However, detailed accounts of patient outcomes are not available. 
Table 1. Thalamic DBS for TS

\begin{tabular}{|c|c|c|c|c|}
\hline $\begin{array}{l}\text { Visser-Vandewalle et al. [24] } \\
\text { (2003) }\end{array}$ & 1 & CM, Spv, Voi & 1 year & $60.5 \%$ reduction in tics \\
\hline Bajwa et al. [27] (2007) & 1 & CM, Spv, Voi & 2 years & $\begin{array}{l}\text { YGTSS score: } 33 \rightarrow 12 \\
\text { YBOCS score: } 29 \rightarrow 8\end{array}$ \\
\hline Shields et al. [49] (2008) & 1 & CM, Spv, Voi & 3 months & $46 \%$ improvement in YGTSS score \\
\hline Porta et al. [31] (2009) & 15 & CM-Pf, Voa & 2 years & $\begin{array}{l}\text { YGTSS score: } 76.5-36.6 \\
\text { YBOCS score: } 20.9-14.4 \\
\text { BDI score: } 30.7-22.7 \\
\text { STAI score: } 44.2-29.5\end{array}$ \\
\hline Ackermans et al. [32] (2010) & 6 & CM, Spv, Voi & 1 year & $\begin{array}{l}\text { YGTSS: } 41.1-25.6 \\
\text { No significant change in YBOCS, BDI } \\
\text { Cognition stable except } \uparrow \text { time needed to complete } \\
\text { Stroop color-word card test }\end{array}$ \\
\hline Savica et al. [33] (2012) & 3 & CM-Pf & 1 year & $70 \%$ reduction in YGTSS \\
\hline
\end{tabular}

\section{Surgical Targets}

\section{Thalamus}

Using Hassler and Dieckmann's [22] experience as a foundation, Vandewalle et al. [23] published the first case of thalamic DBS for TS in 1999. The authors postulated that stimulation of the nucleus ventralis oralis internis would lead to diminished motor and vocal tics through inhibiting projections to the facial parts of the premotor and motor cortex. Stimulation of the intralaminar nuclei would reduce the activity of the dorsal, sensorimotor parts of the striatum, while stimulation of the midline thalamic nuclei would reduce activity in the ventral, limbic striatum [24]. Since that time, the outcomes of thalamic DBS have been reported in about 30 patients with TS (table 1).

The initial surgical target was $5 \mathrm{~mm}$ lateral to the anterior commissure (AC)-posterior commissure (PC) line, $4 \mathrm{~mm}$ posterior to the midcommissural point, and at the level of the AC-PC plane, targeting the centromedian nu- cleus-substantia periventricularis-nucleus ventro-oralis internus complex (CM-Spv-Voi). Intraoperative stimulation was conducted with a Radionics probe with a $2-\mathrm{mm}$ exposed tip. During intraoperative stimulation with a frequency of $100 \mathrm{~Hz}$ and a pulse width of $200 \mu \mathrm{s}$, a pleasant feeling reported by the patient supported an appropriate electrode position [24].

During two of the first implantations, it was necessary to move one brain target $2 \mathrm{~mm}$ medially. In the first patient, an intense feeling as fear was elicited during intraoperative stimulation in the right brain. The electrode was felt to be too lateral and moved $2 \mathrm{~mm}$ medial, with a pleasant feeling elicited during repeat stimulation. In a second case, during implantation of the left electrode, eye deviation was seen at target plus $4 \mathrm{~mm}$. This suggested a position in the mesencephalon, and consequently the electrode was moved $2 \mathrm{~mm}$ more medially [24].

In the initial follow-up of 3 patients implanted using this technique, the authors report a decrease in tic frequency of $90.1 \%$ at 5 years follow-up in patient $1,72.2 \%$ 
reduction at 1 year follow-up in patient 2 , and $82.6 \%$ reduction at 8 months follow-up in patient 3 . The authors shared the long-term follow-up of patient 1 and patient 3 [25]. At 10 years follow-up, patient 1 maintained a reduction in tic frequency of $92.6 \%$. At 6 years follow-up, patient 3 maintained significant benefit with a $78 \%$ improvement from baseline.

In 2007, Maciunas et al. [26] conducted a blinded trial of thalamic stimulation for TS in 5 adult patients. The authors followed the lead of Visser-Vandewalle et al. [24] and used the same stereotactic target for stimulating the anterior extent of the CM-Pf complex. The authors used microelectrode recording during the implantation of the DBS electrodes, and intraoperative stimulation through the DBS electrode after implantation. However, they did not detail whether the microelectrode recording altered their initial surgical target. During the blinded randomization phase of the study, patients were evaluated in four states (both stimulators on, left on-right off, right on-left off, and both off) for 1 week each. This was then followed by an open-label evaluation with 3 months follow-up. The mean improvement in their primary outcome measure of the modified Rush Video-Based Rating scale was 4.2 points during the randomized on-on state, 5.4 points at the beginning of the open-label period, and 2.6 points at 3 months follow-up. Patients were not found to have benefitted from the use of unilateral stimulation. Three out of the 5 patients improved at all time points evaluated using either the modified Rush Video-Based Rating scale or simple tic counts.

Also in 2007, Bajwa et al. [27] reported on a patient implanted using the target described by Visser-Vandewalle et al. [24]. The patient was implanted under general anesthesia, and at baseline his total tic score on the Yale Global Tic Severity Scale (YGTSS) was 33 and his YaleBrown Obsessive Compulsive Scale (YBOCS) score was 29. At 24 months follow-up, the patient's total tic score decreased by $66 \%$ to 12 , and his YBOCS score decreased to less than 10 .

Servello et al. [28] shared their experience with thalamic DBS for TS in 2008. The surgical target for all patients in their series was the CM-Pf complex-ventralis oralis anterior nucleus. The stereotactic coordinates for their target were determined from the SchaltenbrandWahren atlas. However, the indirect coordinates for their target were not provided. Anatomically, the target is similar to that used by Visser-Vandewalle et al. [24], with the goal of broadly modulating cortico-striato-pallido-thalamic circuits. Patients underwent surgery using threechannel microelectrode recording. Stimulation was per- formed through the three channels using a frequency of $100 \mathrm{~Hz}$, a pulse width of $60 \mu \mathrm{s}$, and between 1 and $5 \mathrm{~mA}$ of current. The optimal trajectory for the DBS electrode was chosen based upon the intraoperative stimulation.

Microelectrode recordings and local field potential recordings from the ventralis oralis complex were described by Marceglia et al. [29] in 7 of their patients. Along the trajectory to the target, an irregular pattern of firing was seen 4-6 $\mathrm{mm}$ above target, an oscillatory bursting pattern was seen $1-3 \mathrm{~mm}$ above target, and a relatively silent zone was seen at target. The electrical silence at target can be attributed to the proximity of the white matter of the zona incerta. The oscillatory bursting pattern was seen at frequencies between 2 and $13 \mathrm{~Hz}$. This increased low-frequency activity has also been seen in other hyperkinetic disorders, including dystonia [30].

Porta et al. [31] have reported the 2-year clinical follow-up results for 18 of their patients with thalamic DBS. During the follow-up period, 2 patients did not wish to have the pulse generator anymore, and 1 patient went on to receive GPi implantation for unspecified reasons. Of the remaining 15 patients, the mean baseline score on the YGTSS was 76.5, which improved significantly to 36.6 at 2 years follow-up. A clinically significant improvement was also seen on the YBOCS, the Beck Depression Inventory, and the Spielberger State-Trait Anxiety Inventory (STAI).

Recently, Ackermans et al. [32] presented their series of 6 patients who participated in a prospective, randomized, double-blinded study of stimulation targeting the CM-Spv-Voi complex. Their indirect coordinates were as described by Visser-Vandewalle et al. [24]. Multiple-track microelectrode recording was used, and test stimulation was performed at a frequency of $130 \mathrm{~Hz}$ and a pulse width of $60 \mu$ s between 1 and $6 \mathrm{~mA}$. The authors found a statistically significant improvement on the YGTSS in the onstimulation as compared with the with off-stimulation state. The improvement on the YGTSS was maintained at 1 year follow-up, with a $49 \%$ improvement reported. No significant difference was seen in psychiatric comorbidities including OCD, or neuropsychological testing, except for a lengthening in the time needed to complete the color-word card of the Stroop test.

In 2012, Savica et al. [33] reported the 1-year follow-up of 3 patients who underwent DBS implantation targeting the CM-Pf complex. Their surgical target was $5 \mathrm{~mm}$ lateral and $8 \mathrm{~mm}$ posterior to the midcommissural point, which is a more posterior target than that suggested by Vandewalle et al. [24]. The authors report a mean reduction on the YGTSS of 70\% (range 68-80). 
Table 2. Pallidal DBS for TS

\begin{tabular}{|c|c|c|c|c|}
\hline Author & $\mathrm{n}$ & Target & Follow-up & Outcomes \\
\hline Diederich et al. [36] (2005) & 1 & posteroventral GPi & 14 months & $\begin{array}{l}73 \% \text { reduction in tic frequency; improvement in BDI } \\
\text { and anxiety inventory }\end{array}$ \\
\hline Ackermans et al. [40] (2006) & 1 & posteroventral GPi & 1 year & $93 \%$ reduction in tics \\
\hline Shahed et al. [37] (2007) & 3 & posteroventral GPi & $\begin{array}{l}\text { patient } 1: 1 \text { year } \\
\text { patient } 2: 6 \text { months } \\
\text { patient } 3: 3 \text { months }\end{array}$ & $\begin{array}{l}\text { improvement in YGTSS/YBOCS: } \\
76 / 69 \% \\
35 / 24 \% \\
38 / 22 \%\end{array}$ \\
\hline $\begin{array}{l}\text { Dehning et al. [39] } \\
\text { (2008) }\end{array}$ & 1 & posteroventral GPi & 12 months & $\begin{array}{l}\text { YGTSS score: } 83 \rightarrow 10 \\
\text { no change in neurocognitive outcome }\end{array}$ \\
\hline Welter et al. [42] (2008) & 3 & $\begin{array}{l}\text { CM-Pf and } \\
\text { ventromedial GPi }\end{array}$ & $\begin{array}{l}\text { patient 1: } 60 \text { months } \\
\text { patient 2: } 33 \text { months } \\
\text { patient 3: } 20 \text { months }\end{array}$ & $\begin{array}{l}\text { improvement in YGTSS score: } \\
82 \% \text { with pallidal and thalamic stimulation } \\
\text { stable reduction with pallidal stimulation } \\
74 \% \text { with pallidal and thalamic stimulation }\end{array}$ \\
\hline Dueck et al. [41] (2009) & 1 & posteroventral GPi & & not effective \\
\hline Filho et al. [43] (2007) & 1 & $\mathrm{GPe}$ & 23 months & $\begin{array}{l}81 \% \text { reduction in tic score } \\
84 \% \text { reduction in obsessive-compulsive symptom score }\end{array}$ \\
\hline Gallagher et al. [71] (2006) & 1 & posteroventral GPi & unknown & unknown \\
\hline $\begin{array}{l}\text { Martinez-Fernandez et al. } \\
\text { [46] (2011) }\end{array}$ & 6 & $\begin{array}{l}\text { posteroventral GPi (3); } \\
\text { anteromedial GPi (3) }\end{array}$ & mean 12 months & $\begin{array}{l}\text { improvement in YGTSS score: } 29 \% \\
\text { improvement in YBOCS score: } 26 \%\end{array}$ \\
\hline
\end{tabular}

$\mathrm{BDI}=$ Beck Depression Inventory.

\section{Globus Pallidus}

Pallidotomy [34] along with simulation of the posteroventral GPi [35-41], ventromedial GPi [42] and globus pallidus externus (GPe) [43] has been used in the treatment of TS. However, the number of published case reports using this target is still relatively small (table 2).

Van der Linden et al. [35] published the first report on the efficacy of pallidal stimulation in a patient with TS. The patient underwent implantation of electrodes both in the posteroventral GPi and in the thalamic target as described by Vandewalle et al. [23]. The coordinates for the GPi were $21.5 \mathrm{~mm}$ lateral, $4 \mathrm{~mm}$ anterior, and $3 \mathrm{~mm}$ below the AC-PC plane. During an externalized trial, the patient was found to have an $80 \%$ reduction in tics with thalamic stimulation and a $95 \%$ reduction in tics with pallidal stimulation. The pallidal electrodes were consequently connected with the internal pulse generator. At 6 months follow-up, the benefit from pallidal stimulation was maintained.

In 2005, Diederich et al. [36] reported the 14-month outcome of a 27-year-old man implanted in the posteroventral GPi (17 mm lateral, $4 \mathrm{~mm}$ anterior and $5 \mathrm{~mm}$ be- low the midcommissural point) under general anesthesia. The improvement in tic frequency was progressive with time postoperatively. At 14 months follow-up, the mean tic frequency per minute had decreased by $73 \%$. The patient was also found to have improvement in depressive and anxiety symptoms as measured by the Beck Depression Inventory and the STAI.

The posteroventral GPi has been the target in TS patients with 'malignant' TS treated at our center at Baylor College of Medicine, the results of which have been reported in 3 patients, including the youngest TS patient ever treated with DBS $[37,38,44]$. At 1 year follow-up for patient 1 , the YGTSS score improved by $76 \%$ and the YBOCS score improved by $69 \%$. At 6 months follow-up for patient 2 , the YGTSS score improved by $35 \%$ and the YBOCS score improved by $24 \%$. At 3-month follow-up for patient 3, the YGTSS score improved by $38 \%$, and the YBOCS score improved by $22 \%$. Over longitudinal evaluation, stimulation parameters were high and rechargeable batteries were eventually used [44]. Longitudinal evaluation of a larger series of patients is in process. 
Dehning et al. [39] implanted bilateral posteroventral GPi electrodes ( $3 \mathrm{~mm}$ anterior to midcommissural point, $20 \mathrm{~mm}$ lateral, and $4 \mathrm{~mm}$ below the AC-PC plane) in a 44-year-old woman with TS. At 1 year follow-up, the YGTSS score improved from 83 preoperatively to 10 , and no change in neurocognitive outcome was detected using the Verbal Learning Memory Test or the Stroop Test. The authors report that this benefit has been maintained at 4 years follow-up [45]. In a more recent report, the authors share the results of 4 patients who underwent GPi DBS for TS. Two patients responded well to DBS, and 2 patients were nonresponders who ultimately ceased use of their DBS. Interestingly, the authors note that the 2 patients who responded to DBS also responded preoperatively to electroconvulsive therapy. Larger studies will be needed to determine whether a true correlation exists [45].

A recent randomized, blinded study compared the efficacy of DBS targeting the CM-Pf complex with DBS of the ventromedial GPi in 3 patients with treatment-refractory TS [42]. In contrast to other studies, the ventromedial GPi was chosen to more selectively target the limbic and associative fibers of the GPi. The mean coordinates for the ventromedial GPi were $20 \mathrm{~mm}$ anterior to the PC, $12 \mathrm{~mm}$ lateral to midline and $3 \mathrm{~mm}$ ventral to the AC-PC plane. With therapeutic GPi stimulation, an improvement in the YGTSS score of 65,96 , and $74 \%$ was seen in patients 1,2, and 3, respectively. Stimulation of the CMPf complex led to a reduction in the YGTSS score by 64, 30 , and $40 \%$ in patients 1,2 , and 3 , respectively. Simultaneous pallidal and thalamic stimulation did not improve the clinical outcome, with a reduction in the YGTSS score of 60,43 , and $76 \%$. Interestingly, however, at the last follow-up (60 and 20 months), 2 of the 3 patients were using simultaneous pallidal and thalamic stimulation.

Stimulation of the GPe has also been proposed [43]. In 2007, Filho et al. [43] reported on implantation of the GPe in the treatment of TS in which the stereotactic coordinates for the target were $3 \mathrm{~mm}$ posterior and superior to the AC and $20 \mathrm{~mm}$ lateral to the AC. A double-blind evaluation was performed which revealed an $81 \%$ reduction in tic scores and a $84 \%$ reduction in obsessive compulsive symptom scores at 23 months follow-up. An ongoing prospective controlled study is underway.

In 2011, Martinez-Fernandez et al. [46] reported their experience with 5 patients who underwent 6 surgical implantations into the GPi for TS. Three patients were implanted in the posteroventral GPi, and 2 patients were implanted in the anteromedial GPi. Anatomical targeting of the anteromedial GPi was based on proton density
MRI, the goal being stimulation of the limbic GPi as used by Welter et al. [42]. One of the patients initially implanted in the posteroventral GPi was revised to the anteromedial target due to capsular side effects limiting the level of stimulation. They report the follow-up for the 6 implantations performed in these 5 patients, over a mean followup of 1 year. The mean YGTSS score decreased by $29 \%$ from 77.8 to 54.2, and the mean YBOCS score decreased from 16.3 preoperatively to 10.8 postoperatively, an improvement which was maintained at last follow-up. One patient underwent posteroventral GPi stimulation due to coexistent neuroleptic-induced dystonia; other targeting decisions were made at the discretion of the authors with unspecified criteria. In the authors' opinion, anteromedial GPi stimulation was more effective in the timeframe of evaluation.

\section{Anterior Limb of the Internal Capsule/Nucleus Accumbens}

Stimulation of the anterior limb of the internal capsule has become one favored treatment strategy for OCD that has been resistant to pharmacological and cognitive behavioral therapies [47]. Given the common association between TS and OCD, case reports have been published using this surgical target (table 3).

In 2005, Flaherty et al. [48] reported on a patient with TS who was treated with DBS of the anterior limb internal capsule. The authors' target was $12 \mathrm{~mm}$ lateral to the AC, $7 \mathrm{~mm}$ below the $\mathrm{AC}$, and at the midpoint of the anterior limb of the internal capsule. At 18 months follow-up, the patient experienced a 23\% improvement in global severity on the YGTSS. As the patient did not experience a more complete resolution of her tics, when a hardware malfunction occurred, she was revised to the thalamic target with a $46 \%$ decrease in global severity on the YGTSS [49].

In 2007, Kuhn et al. [50] reported a patient with comorbid OCD and TS. The stereotactic coordinate of the surgical target was determined to be $2.5 \mathrm{~mm}$ rostral to the $\mathrm{AC}, 6.5 \mathrm{~mm}$ lateral of the $\mathrm{AC}$, and $4.5 \mathrm{~mm}$ ventral to the AC. Postoperative imaging revealed contacts 0 and 1 to be located within the nucleus accumbens, and contacts 2 and 3 to be located within the anterior limb of the internal capsule. The optimal therapeutic electrode configuration proved to be case positive, electrodes $0-, 1-, 2-, 3-$. At 30 months follow-up, the YGTSS score decreased from 90 preoperatively to 53, and the YBOCS score decreased from 25 preoperatively to 12 .

Neuner et al. [51], in 2009, similarly reported the 36-month follow-up of a patient with TS and comorbid 
Table 3. Other DBS targeting strategies used for TS

\begin{tabular}{|c|c|c|c|c|}
\hline Kuhn et al. [50] (2007) & 1 & ALIC/NA & 30 months & $\begin{array}{l}\text { YGTSS score: } 90 \rightarrow 53 \\
\text { YBOCS score: } 25 \rightarrow 12\end{array}$ \\
\hline Shields et al. [49] (2008) & 1 & $\begin{array}{l}\text { ALIC (revised } \\
\text { to thalamus) }\end{array}$ & 18 months & $23 \%$ improvement in YGTTS score \\
\hline Burdick et al. [52] (2010) & 1 (mild TS, severe OCD) & ALIC & 30 months & YGTSS score worsened $17 \%$ in first 6 months \\
\hline $\begin{array}{l}\text { Martinez-Torres et al. [73] } \\
\text { (2009) }\end{array}$ & 1 (PD and TS) & STN & 1 year & $\begin{array}{l}89 \% \text { reduction in tics }-6 \text { months } \\
97 \% \text { reduction in tics }-1 \text { year }\end{array}$ \\
\hline
\end{tabular}

ALIC = Anterior limb internal capsule; NA = nucleus accumbens; PD = Parkinson's disease; STN = subthalamic nucleus.

OCD who was treated by the same surgical team with DBS of the nucleus accumbens and anterior limb of the internal capsule. The same stereotactic target was used $(2.5 \mathrm{~mm}$ rostral to the AC, $6.5 \mathrm{~mm}$ lateral, and $4.5 \mathrm{~mm}$ ventral to the $\mathrm{AC}$ ), and postoperative imaging revealed the distal two contacts to be located with the nucleus accumbens and the two proximal contacts to be located within the anterior limb of the internal capsule. This patient received maximal therapeutic benefit through an electrode configuration of case positive, and electrodes 0 - and 1-. At 36 months follow-up, the YGTSS score decreased from 100 before treatment to 56. A significant reduction in the YBOCS score was also seen at 36 months: it decreased to 15 from a preoperative value of 32 .

Finally, in 2010, Burdick et al. [52] reported on a patient with severe OCD and mild TS who was implanted in the anterior limb of the internal capsule and nucleus accumbens. The authors note that though the patient felt subjective improvement in the vocal and motor tics, objective assessment did not reveal any improvement.

\section{Current Guidelines for Patient Management}

\section{Patient Selection}

In 2006, the recommendations from the Tourette Syndrome Association panel of experts recommended inclusion criteria and guidelines for pre- and postoperative evaluation (table 4) [53]. The first requirement is a diagnosis of TS, which by the DSM-IV requires multiple motor, and one or more vocal tics to be present at some time
Table 4. Inclusion criteria [53]

\section{Age $>25$ years}

YGTSS score $>35 / 50$ for at least 12 months

Failed conventional medical therapy from 3 pharmacological classes $\alpha$-Adrenergic agonist

Two dopamine antagonists

Benzodiazepine

Evaluation for behavioral interventions to reduce tic severity

during the illness although not necessarily concurrently. The tics must occur many times nearly every day, have been present for greater than 1 year, and there can not have been a period of greater than 3 months without tics. The age of onset must be before the age of 18 , and the symptoms can not be secondary to a medical condition.

Once the diagnosis of TS is established, a thorough medical and cognitive behavioral treatment strategy should be initiated. The patient should have undergone treatment trials with three classes of medications including an $\alpha$-adrenergic agonist, two dopamine antagonists and a benzodiazepine. Only if these medications have proven to lack efficacy or have a high side effect profile, should DBS be considered. A high rate of infectious complications of up to $18 \%$ has been reported with DBS for TS, and patients and families should be carefully counseled with regard to the potential risks associated with the procedure [54]. Behavioral traits, such as a compulsion to touch surgical scars and palpable hardware, may contrib- 
ute to a higher complication rate. In addition, immunological abnormalities have been demonstrated in patients with TS, another factor which may contribute to the increased rate of complications [54]. The use of protective devices such as helmets and thoracolumbar orthoses may help to reduce these complications.

Patients considered for DBS should have severe functional impairment that can not be managed medically [5]. The YGTSS should be used to assess the patient's symptoms, and the tic severity score should be greater than 35 out of 50. Patients should also have undergone a psychiatric evaluation to determine whether cognitive behavioral therapy may be effective to control symptoms.

\section{Considerations in Target Selection}

Disturbances in relay pathways involving corticalstriatal-thalamic-cortical circuits have been implicated in the pathophysiology of TS. More specifically, a failure in cortical inhibition of basal-ganglia pathways is hypothesized to lead to the generation of tics [9]. The surgical targets for DBS seek to modulate these circuits. The largest surgical experience for TS to date is with DBS of the medial thalamus. The ability of the CM-Pf nuclei to modulate both sensorimotor and limbic circuitry supports the role of this target in the surgical treatment of TS. Reports of significant improvement in tic severity scores including in randomized studies warrant further studies of this target in the treatment of TS [24, 25, 31]. However, conflicting information is available regarding the effect on comorbidities following stimulation in this region (table 1). Since TS is recognized as a neurobehavioral disorder in which comorbidities are common and often disabling [6], and DBS is recognized as an effective therapy in severe, medication-refractory OCD [46], it is prudent to consider the effect of DBS in TS on symptoms such as comorbid OCD.

One proposed neurobiological model of TS hypothesizes the existence of aberrant foci of striatal neurons that become inappropriately active [3]. These foci of striatal overactivity lead to altered output to the GPi and substantia nigra, which in turn causes an imbalance of the normal promotion of voluntary movements and suppression of involuntary movements. Thus, neuromodulation of the GPi can serve to counteract the overactive striatal output. The large experience with GPi in treating levodopa-induced dyskinesias and dystonia underscore its effectiveness in the modulation of hyperkinetic movement disorders, and this rationale may also apply to the treatment of tics. In addition, its extensive connections with both motor and limbic circuitry provide an anatomical basis for the potential to improve both motor aspects and psychiatric comorbidities of TS. GPi is also a safe target for neuromodulation, with no serious stimulation-induced side effects and a safe neurocognitive profile [55].

Tics and dystonia share certain commonalities. Some tics are in fact described as 'dystonic' and are often the most disabling for patients with TS. In some patients, the two disorders coexist $[56,57]$. Electrophysiological studies have further supported this concept as internal pallidal neurons demonstrate similar firing patterns in patients with TS and patients with dystonia [34]. In their analysis of 8 patients who underwent microelectrodeguided pallidotomy in the treatment of TS, Zhuang et al. [34] found a reduced mean discharge frequency in GPi neurons, with a mean rate of $42.7 \mathrm{~Hz}$. They also describe an intermittent pattern of firing in the internal pallidum, with a repetitive and stereotyped pattern. One year following pallidotomy, the mean reduction in motor tic score was $75 \%$.

Neurobiological studies also support the role of the GPi in the pathophysiology of TS. Postmortem analysis of basal-ganglia tissue from patients with TS revealed a higher number of total neurons in the GPi of TS patients [58]. In addition, a lower neuron number was seen in the GPe and the caudate. This migratory defect of GABAergic neurons, with a resultant alteration in GPi architecture, lends support to targeted neuromodulation of this structure. Further, retrograde neuronal transmission studies in cebus monkeys have demonstrated the extent of cortical projections from the GPi to the prefrontal areas [59]. Approximately one-third of projections from the GPi are directed to the prefrontal cortex, similar to the volume of projections to the motor areas. Thus, stimulation of the traditional motor GPi target in TS patients can be postulated to impact comorbidities via prefrontal connections.

The targeting of the 'limbic' GPi (anteromedial/ventromedial) as opposed to the traditional motor region (posteroventral) deserves some consideration as continuing research broadens our understanding of the limbic connections of the globus pallidus. It is recognized that the ventral portion of the pallidum also serves as a primary output for the ventral striatum/nucleus accumbens [59]. In this regard, the ventral pallidum serves as a critical relay station for translating limbic motivational signals into motor output. As previously discussed, one theory of TS pathogenesis suggests interplay between limbic and sensorimotor circuits [17]. Hence, the GPi may be uniquely positioned to target both the motor and comorbid symptoms of TS from multiple relay pathways (fig. 1). 
Table 5. Parameters for GPi stimulation in TS

\begin{tabular}{|c|c|c|c|c|c|}
\hline Diederich et al. [36] (2005) & posteroventral GPi & 60 & 185 & 2 & $0-, 1+$ \\
\hline Ackermans et al. [40] (2006) & posteroventral GPi & 210 & 170 & 3.1 & case,$+ 0-, 1-, 2-$ \\
\hline $\begin{array}{l}\text { Shahed et al. [37] (2007) } \\
\text { Patient } 1 \\
\text { Patient } 2 \\
\text { Patient } 3\end{array}$ & posteroventral GPi & $\begin{array}{r}90 \\
90 \\
270\end{array}$ & $\begin{array}{l}160 / 145 \\
185 \\
185\end{array}$ & $\begin{array}{l}5 \\
4.7 \\
4.8\end{array}$ & $\begin{array}{l}\text { case }+, 2_{-} \\
\text {case }+, 2_{-} \\
\text {case }+, 2_{-}\end{array}$ \\
\hline Dehning et al. [39] (2008) & posteroventral GPi & 210 & 145 & 4.2 & $\begin{array}{l}\text { right: case }+, 2- \\
\text { left: case }+, 1-\end{array}$ \\
\hline $\begin{array}{l}\text { Martinez-Fernandez et al. [46] (2011) } \\
\text { Patient } 1 \\
\text { Patient } 2\end{array}$ & posteroventral GPi & $\begin{array}{r}150 \\
60 \\
\end{array}$ & $\begin{array}{l}170 \\
130\end{array}$ & $\begin{array}{l}2.5 \\
2.5 \\
\end{array}$ & $\begin{array}{l}\text { case }+3- \\
\text { case }+0-\end{array}$ \\
\hline
\end{tabular}

PW = Pulse width.

Table 6. Parameters for thalamic stimulation in TS

\begin{tabular}{|c|c|c|c|c|c|}
\hline Visser-Vandewalle et al. [24] (2003) & CM, Spv, Voi & 210 & 65 & $3.0 / 2.7$ & left: $\mathrm{C}+/ 4-;$ right: $\mathrm{C}+/ 2-3-$ \\
\hline Bajwa et al. [27] (2007) & CM, Spv, Voi & 90 & 130 & $2.0 / 2.0$ & left: $1-, 3+;$ right: $2-; 4+$ \\
\hline $\begin{array}{l}\text { Maciunas et al. [26] (2007) } \\
\text { Patient } 1 \\
\text { Patient } 2 \\
\text { Patient } 3 \\
\text { Patient } 4 \\
\text { Patient } 5\end{array}$ & CM, Spv, Voi & $\begin{array}{l}90 \\
210 \\
120 \\
120 \\
120 / 90\end{array}$ & $\begin{array}{l}160 / 130 \\
185 \\
130 \\
170 / 185 \\
130\end{array}$ & $\begin{array}{l}3.6 / 3.5 \\
3.6 / 3.6 \\
3.6 / 3.6 \\
3.6 / 3.6 \\
3.5 / 3.6\end{array}$ & $\begin{array}{l}\text { left: } \mathrm{C}+, 2-, 3-; \text { right: } \mathrm{C}+, 3- \\
\text { left: } 2+, 3-; \text { right: } 2+, 3- \\
\text { left: } \mathrm{C}+, 3-; \text { right: } \mathrm{C}+, 3- \\
\text { left: } \mathrm{C}+, 2-, 3-; \text { right: } \mathrm{C}+, 2-, 3- \\
\text { left: } 1-, 3+; \text { right: } 1-, 3+\end{array}$ \\
\hline $\begin{array}{l}\text { Ackermans et al. [25] (2010) } \\
\text { Patient } 1 \\
\text { Patient } 2\end{array}$ & CM, Spv, Voi & $\begin{array}{r}90 \\
150\end{array}$ & $\begin{array}{l}130 \\
100\end{array}$ & $\begin{array}{l}1.8 / 1.5 \\
8.5 / 8.5\end{array}$ & $\begin{array}{l}\text { left: } 0-, 1,2+, 3+; \text { right: } C+, 1- \\
\text { left: } 1-, 2+, 3-; \text { right: } 1-, 2+3-\end{array}$ \\
\hline
\end{tabular}


Patients implanted in all three surgical targets have been reported to have improvements on scales measuring obsessive-compulsive symptoms and anxiety though the data are inconsistently reported across the various reports (table 1). In the largest open-label series [31], 15 patients who underwent bilateral thalamic stimulation experienced a reduction of $31 \%$ in the mean YBOCS score, $26 \%$ in the mean Beck Depression Inventory score, and $33 \%$ in the STAI at a follow-up of 24 months. However, in a 12-month double-blind randomized trial of thalamic stimulation [32], no changes in psychiatric comorbidities were found. Although individual reports of improvement in psychiatric comorbidities have been published (table 2), the numbers are small and no randomized, controlled trials of GPi stimulation exist.

Only three studies provide some insight into the relative efficacy of the various surgical targets used for DBS in TS [35, 42, 49]. Van der Linden et al. [35] compared posteroventral pallidal stimulation with medial thalamic stimulation and Welter et al. [42] compared ventromedial pallidal stimulation with medial thalamic stimulation. All 4 patients reported in these two studies experienced greater reduction in tic scores with pallidal stimulation than with thalamic stimulation. The only other direct comparison that exists is the report by Shields et al. [49]. Their patient was initially implanted in the anterior limb internal capsule with a $23 \%$ reduction in the YGTSS score and was revised to the thalamic target with a greater reduction (46\%) in the YGTSS score. Despite these reports, the lack of randomized, controlled studies between targets makes definitive conclusions about relative efficacy impossible.

Experience in optimizing stimulation parameters for DBS in TS is increasing. Stimulation parameters were available for 11 patients implanted with DBS in the GPi (table 5). At last follow-up, the frequencies ranged from 20 to $185 \mathrm{~Hz}$, pulse widths from 60 to $270 \mu \mathrm{s}$ and amplitudes from 2 to $5 \mathrm{~V}$. The optimized stimulation parameters at last follow-up for thalamic stimulation were equally varied (table 6). The frequencies ranged between 65 and $185 \mathrm{~Hz}$, pulse widths between 60 and $210 \mu \mathrm{s}$ and amplitudes from 2 to $8.5 \mathrm{~V}$.

\section{Future Directions}

Our understanding of the pathophysiology and surgical treatment of Parkinson's disease has grown considerably, partly due to the availability of primate models. Unfortunately, no such model exists for TS. However, imag- ing studies have helped augment our understanding of TS and the structures involved in the pathogenesis. Studies of brain MRI in patients with TS demonstrate an enlargement of lateral thalamic nuclei, and reduced cortical thickness in affected individuals compared with normal controls [61-63]. Caudate volumes have been reported to correlate significantly and inversely with the severity of tic and OCD in young adults with TS [64]. Other differences noted in adult and pediatric patients with TS include reduced volumes of the lenticular and caudate nuclei $[65,66]$. Functional imaging studies with $\left[{ }^{15} \mathrm{O}\right] \mathrm{H}_{2} \mathrm{O}$ positron emission tomography (PET) have shown thalamic and putamen activation with tics [67], while bloodoxygen-level-dependent functional magnetic resonance imaging (BOLD fMRI) has shown decreased activity in the ventral globus pallidus, putamen and midbody of the thalamus during tic suppression [66]. Studies utilizing $\left[{ }^{18} \mathrm{~F}\right]$ fluorodeoxyglucose PET have identified two patterns associated with TS: pattern 1 is characterized by increased metabolic activity in the lateral premotor and supplementary motor association cortices and in the midbrain, whereas pattern 2 is manifested by decreased metabolic activity in the caudate and thalamic areas (limbic basal ganglia-thalamocortical projection system) [68]. Pattern 1 is reportedly associated with tics and pattern 2 correlates with the overall severity of TS. In a follow-up study, involving 12 TS adult patients (untreated for $>2$ years) and 12 controls, the investigators found a TS-related metabolic pattern which was characterized by increased premotor cortex and cerebellum activity and reduced resting activity of the striatum and orbitofrontal cortex [69]. Application of advanced imaging modalities, including diffusion tensor imaging, will continue to expand our knowledge.

The exploration of DBS as treatment modality for TS was based on early experiences with ablative intracranial stereotaxis. To date, the largest experience has been with targeting the thalamus. The pallidum, however, seems to be gaining increasing support as a potential target as GPi DBS has been shown to improve not only tics but also some of the behavioral comorbidities, particularly OCD. However, determination of the optimal surgical target and stimulation parameters will require close multicenter collaboration, standardized methods for evaluating not only the TS-related symptoms but also surgical technique, and rigorous monitoring of postoperative outcomes.
Viswanathan/Jimenez-Shahed/ Baizabal Carvallo/Jankovic 


\section{References}

$>1$ Jankovic J: Tourette's syndrome. N Engl J 17 Groenewegen HJ, van den Heuvel OA, Cath Med 2001;354:1184-1192.

$>2$ Jankovic J, Gelineua-Kattner R, Davidson A: Tourette's syndrome in adults. Mov Disord 2010;25:2171-2175.

-3 Albin RL, MinkJW: Recent advances in Tourette syndrome research. Trends Neurosci 2006;29:175-182.

4 Jankovic J, Kurlan R: Tourette syndrome: evolving concepts. Mov Disord 2011;26: 1149-1156.

5 Jankovic J: Treatment of hyperkinetic movement disorders. Lancet Neurol 2009;8:844856.

6 Cheung MY, Shahed J, Jankovic J: Malignant Tourette syndrome. Mov Disord 2007;22: 1743-1750.

7 Mink JW: Neurobiology of basal ganglia and Tourette syndrome: basal ganglia circuits and thalamocortical outputs. Adv Neurol 2006;99:89-98.

$>8$ Utter AA, Basso MA: The basal ganglia: an overview of circuits and function. Neurosci Biobehav Rev 2008;32:333-342.

$>9$ Mink JW: Basal ganglia dysfunction in Tourette's syndrome: a new hypothesis. Pediatr Neurol 2001;25:190-198.

>10 Grabli D, McCairn K, Hirsch EC, Agid Y, Feger J, Francois C, Tremblay L: Behavioral disorders induced by external globus pallidus dysfunction in primates. I. Behavioral study. Brain 2004,127:2039-2054.

11 Mink JW: The basal ganglia and involuntary movements: impaired inhibition of competing motor patterns. Arch Neurol 2003,60 1365-1368.

12 Sadikot AF, Rymar VV: The primate centromedian-parafascicular complex: anatomical organization with a note on neuromodulation. Brain Res Bull 2009;78:122-130.

- 13 Kimura M, Minamimoto T, Matsumoto N, Hori Y: Monitoring and switching of corticobasal ganglia loop functions by the thalamostriatal system. Neurosci Res 2004;48:355360 .

$>14$ Van der Werf YD, Witter MP, Groenewegen $\mathrm{HJ}$ : The intralaminar and midline nuclei of the thalamus. Anatomical and functional evidence for participation in processes of arousal and awareness. Brain Res Rev 2002; 39:107-140.

$\checkmark 15$ Matsumoto N, Minamimoto T, Graybiel AM, Kimura M: Neurons in the thalamic CM-Pf complex supply striatal neurons with information about behaviorally significant sensory events. J Neurophysiol 2001;85:960976.

$\checkmark 16$ Sidibé M, Paré JF, Smith Y: Nigral and pallidal inputs to functionally segregated thalamostriatal neurons in the centromedian/ parafascicular intralaminar nuclear complex in monkey. J Comp Neurol 2002;447: 286-299.
DC, Voorn P, Veltman DJ: Does an imbalance between the dorsal and ventral striatopallidal systems play a role in Tourette's syndrome? A neuronal circuit approach. Brain Dev 2003;25(suppl 1):S3-S14.

18 Temel Y, Visser-Vandewalle V: Surgery in Tourette syndrome. Mov Disord 2004;91:314.

19 Rauch SL, Baer L, Cosgrove GR, Jenike MA: Neurosurgical treatment of Tourette's syndrome: a critical review. Compr Psychiatry 1995;36:141-156.

20 Robertson M, Doran M, Trimble M, Lees AJ: The treatment of Gilles de la Tourette syndrome by limbic leucotomy. J Neurol Neurosurg Psychiatry 1990;53:691-694.

21 Rickards H, Wood C, Cavanna AE: Hassler and Dieckmann's seminal paper on stereotactic thalamotomy for Gilles de la Tourette syndrome: translation and critical reappraisal. Mov Disord 2008;23:1966-1972.

22 Hassler R, Dieckmann G: Stereotaxic treatment of tics and inarticulate cries or coprolalia considered as motor obsessional phenomena in Gilles de la Tourette's disease (in French). Rev Neurol (Paris) 1970;123:89-100.

23 Vandewalle V, van der Linden C, Groenewegen HJ, Caemaert J: Stereotactic treatment of Gilles de la Tourette syndrome by high frequency stimulation of the thalamus. Lancet 1999;353:724.

24 Visser-Vandewalle V, Temel Y, Boon P, Vreeling F, Colle H, Hoogland G, et al: Chronic bilateral thalamic stimulation: a new therapeutic approach in intractable Tourette syndrome. J Neurosurg 2003;99: 1094-1100.

25 Ackermans L, Duits A, Temel Y, Winogrodzka A, Peeters F, Beuls EA, et al: Long-term outcome of thalamic deep brain stimulation in two patients with Tourette syndrome. J Neurol Neurosurg Psychiatry 2010;81:10681072.

-26 Maciunas RJ, Maddux BN, Riley DE, Whitney CM, Schoenberg MR, Ogrocki PJ, et al: Prospective randomized double-blind trial of bilateral thalamic deep brain stimulation in adults with Tourette syndrome. J Neurosurg 2007; 107:1004-1014.

27 Bajwa RJ, de Lotbinière AJ, King RA, Jabbari B, Quatrano S, Kunze K, et al: Deep brain stimulation in Tourette's syndrome. Mov Disord 2007;22:1346-1350.

28 Servello D, Porta M, Sassi M, Brambilla A, Robertson MM: Deep brain stimulation in 18 patients with severe Gilles de la Tourette syndrome refractory to treatment: the surgery and stimulation. J Neurol Neurosurg Psychiatry 2008;79:136-142.

29 Marceglia S, Servello D, Foffani G, Porta M, Sassi M, Mrakic-Sposta S, et al: Thalamic single-unit and local field potential activity in Tourette syndrome. Mov Disord 2010;25: 300-308.
30 Silberstein P, Kuhn AA, Kupsch A, Trottenberg T, Krauss JK, Wöhrle JC, et al: Patterning of globus pallidus local field potentials differs between Parkinson's disease and dystonia. Brain 2003;126:2597-2608.

-31 Porta M, Brambilla A, Cavanna AE, Servello D, Sassi M, Rickards H: Thalamic deep brain stimulation for treatment-refractory Tourette syndrome: two-year outcome. Neurology 2009;73:1375-1380.

32 Ackermans L, Duits A, van der Linden C, Tijssen, Schruers K, Temel Y, et al: Doubleblind clinical trial of thalamic stimulation in patients with Tourette syndrome. Brain 2011;134:832-844.

33 Savica R, Stead M, Mack KJ, Lee KH, Klassen BT: Deep brain stimulation in Tourette syndrome: a description of 3 patients with excellent outcome. Mayo Clin Proc 2012;87:5962.

34 Zhuang P, Hallett M, Zhang X, Li J, Zhang Y, Li Y: Neuronal activity in the globus pallidus internus in patients with tics. J Neurol Neurosurg Psychiatry 2009;80:1075-1081.

35 Van der Linden C, Colle H, Vandewalle V, Alessi G, Rijckaert D, De Waele L: Successful treatment of tics with bilateral internal pallidum stimulation in a 27 -year old male patient with Gilles de la Tourette's syndrome. Mov Disord 2002;17:S343.

36 Diederich NJ, Kalteis K, Stamenkovic M, Pieri V, Alesch F: Efficient internal pallidal stimulation in Gilles de la Tourette syndrome: a case report. Mov Disord 2005;20: 1496-1520.

37 Shahed J, Poysky J, Kenney C, Simpson R, Jankovic J: GPi deep brain stimulation for Tourette syndrome improves tics and psychiatric comorbidities. Neurology 2007;68: 159-160.

38 Shahed J, Poysky J, Kenney C, Simpson R, Jankovic J: Motor and behavioral outcomes after bilateral GPi deep brain stimulation for severe Tourette syndrome. The Movement Disorder Society's 11th International Congress of Parkinson's Disease and Movement Disorders 2007, abstract No 950701.

39 Dehning S, Mehrkens JH, Mueller N, Botzel K: Therapy-refractory Tourette syndrome: beneficial outcome with globus pallidus internus deep brain stimulation. Mov Disord 2008;23:1300-1302.

40 Ackermans L, Temel Y, Cath D, van der Linden C, Bruggeman R, Kleijer M, et al: Deep brain stimulation in Tourette's syndrome: Two targets? Mov Disord 2006;21:709-713.

41 Dueck A, Wolters A, Wunsch K, BohneSuraj S, Mueller JU, Haessler F, et al: Deep brain stimulation of globus pallidus internus in a 16-year old boy with severe Tourette syndrome and mental retardation. Neuropediatrics 2009;40:239-242. 
42 Welter ML, Mallet L, Houeto JL, Karachi C, Czernecki V, Cornu P, et al: Internal pallidal and thalamic stimulation in patients with Tourette syndrome. Acta Neurol 2008;65: 952-957.

43 Filho OV, Ragazzo PC, Silva DJ, Sousa JT, Ribeiro TMC, Oliveira PM: Bilateral globus pallidus externus deep brain stimulation for the treatment of Tourette syndrome: an ongoing prospective controlled study. Stereotact Funct Neurosurg 2007;85:42-43.

44 Jimenez-Shahed J: Programming parameters and outcome in GPi deep brain stimulation (DBS) for Tourette syndrome (TS). The Movement Disorder Society's 15th International Congress of Parkinson's Disease and Movement Disorders 2011, abstract No 551397.

-45 Dehning S, Feddersen B, Cerovecki A, Botzel K, Muller N, Mehrkens JH: Globus pallidus internus-deep brain stimulation in Tourette's syndrome: can clinical symptoms predict response. Mov Disord 2011;26:2440 2441.

46 Martinez-Fernandez R, Zrinzo L, Aviles-Olmos I, Hariz M, Martinez-Torres I, Joyce E, et al: Deep brain stimulation for Gilles de la Tourette syndrome: a case series targeting subregions of the globus pallidus internus. Mov Disord 2011;26:1922-1930.

47 Milan MK, Campos M, Sheth SA, Eskandar EN: Deep brain stimulation for obsessivecompulsive disorder: past, present, and future. Neurosurg Focus 2010;29:E10.

-48 Flaherty AW, Williams ZM, Amirnovin R, Kasper E, Rauch SL, Cosgrove GR, et al: Deep brain stimulation of the anterior internal capsule for the treatment of Tourette syndrome: technical case report. Neurosurgery 2005;57:E403.

49 Shields DC, Cheng ML, Flaherty AW, Gale JT, Eskandar EN: Microelectrode-guided deep brain stimulation for Tourette syndrome: within-subject comparison of different stimulation sites. Stereotact Funct Neurosurg 2008;86:87-91.

50 Kuhn J, Lenartz D, Mai JK, Huff W, Lee SH, Koulousakis A, et al: Deep brain stimulation of the nucleus accumbens and the internal capsule in therapeutically refractory Tourette-syndrome. J Neurol 2007;254:963-965.
Neuner I, Podoll K, Lenartz D, Sturm V, Schneider F: Deep brain stimulation in the nucleus accumbens for intractable Tourette's syndrome: follow-up report of 36 months. Biol Psychiatry 2009;65:e5-e6.

52 Burdick A, Foote KD, Goodman W, Ward HE, Ricciuti N, Murphy T, et al: Lack of benefit of accumbens/capsular deep brain stimulation in a patient with both tics and obsessive-compulsive disorder. Neurocase 2010; 16:321-330.

53 Mink JW, Walkup J, Frey KA, Como P, Cath $\mathrm{D}$, Delong MR, et al: Patient selection and assessment recommendations for deep brain stimulation in Tourette syndrome. Mov Disord 2006;21:1831-1838.

54 Servello D, Sassi M, Gaeta M, Ricci C, Porta M: Tourette syndrome (TS) bears a higher rate of inflammatory complications at the implanted hardware in deep brain stimulation (DBS). Acta Neurochir 2011;153:629-632.

55 Cavanna AE, Eddy CM, Mitchell R, Pall H, Mitchell I, Zrinzo L, Foltynie T, Jahanshahi M, Limousin P, Hariz MI, Rickards H: An approach to deep brain stimulation for severe treatment-refractory Tourette syndrome: the UK perspective. Br J Neurosurg 2011;25:38-44.

56 Yaltho TC, Jankovic J, Lotze T: The association of Tourette syndrome and dopa-responsive dystonia. Mov Disord 2010;26:359-360.

57 Welter ML, Grabli D, Vidailhet M: Deep brain stimulation for hyperkinetic disorders: dystonia, tardive dyskinesia, and tics. Curr Opin Neurol 2010;23:420-425.

58 Kalanithi PS, Zheng W, Kataoka Y, DiFiglia M, Grantz H, Saper CB, et al: Altered parvalbumin-positive neuron distribution in basal ganglia of individuals with Tourette syndrome. Proc Natl Acad Sci USA 2005;102: 13307-13312.

59 Middleton FA, Strick PL: Basal-ganglia projections to the prefrontal cortex of the primate. Cereb Cortex 2002;12:926-935.

60 Smith KS, Tindell AJ, Aldridge JW, Berridge KC: Ventral pallidum roles in reward and motivation. Behav Brain Res 2009;196:155167.

61 Miller AM, Bansal R, Hao X, Sanchez-Pena JP, Sobel LJ, Liu J, et al: Enlargement of thalamic nuclei in Tourette syndrome. Arch Gen Psychiatry 2010;67:955-964.

- 62 Worbe Y, Gerardin E, Hartmann A, Valabrégue R, Chupin M, Tremblay L, et al: Distinct structural changes underpin clinical phenotypes in patients with Gilles de la Tourette syndrome. Brain 2010;133:36493660
63 Draganski B, Martino D, Cavanna AE, Hutton C, Orth M, Robertson MM, et al: Multispectral brain morphometry in Tourette syndrome persisting into adulthood. Brain 2010;133:3661-3675.

64 Bloch MH, Leckman JF, Zhu H, Peterson BS: Caudate volumes in childhood predict symptom severity in adults with Tourette syndrome. Neurology 2005;65:1253-1258.

65 Peterson BS, Thomas P, Kane MJ, Scahill L, Zhang H, Bronen R, et al: Basal Ganglia volumes in patients with Gilles de la Tourette syndrome. Arch Gen Psychiatry 2003;60: 415-424.

66 Peterson BS, Skudlarski P, Anderson AW, Zhang H, Gatenby JC, Lacadie CM, et al: A functional magnetic resonance imaging study of tic suppression in Tourette's syndrome. Arch Gen Psychiatry 1998;54:326333.

-67 Lerner A, Bagic A, Boudreau EA, Hanakawa T, Pagan F, Mari Z, et al: Neuroimaging of neuronal circuits involved in tic generation in patients with Tourette syndrome. Neurology 2007;68:1979-1987.

68 Eidelberg D, Moeller JR, Antonini A, Kazumata K, Dhawan V, Budman C, et al: The metabolic anatomy of Tourette's syndrome. Neurology 1997;48:927-934.

69 Pourfar M, Feigin A, Tang CC, Carbon-Correll M, Bussa M, Budman C, et al: Abnormal metabolic brain networks in Tourette syndrome. Neurology 2011;76:944-952.

70 Goetz CG, Pappert EJ, Louis ED, Raman R, Leurgans S: Advantages of a modified scoring method for the Rush Video-Based Tic Rating Scale. Mov Disord 1999;14:502-506.

-71 Gallagher CL, Garell PC, Montgomery EB Jr: Hemi tics and deep brain stimulation. Neurology 2006;66:E12.

72 Zabek M, Sobstyl M, Koziara H, Dzierzecki $S$ : Deep brain stimulation of the right nucleus accumbens in a patient with Tourette syndrome. Neurol Neurochir Pol 2008;42:554559.

73 Martinez-Torres I, Hariz MI, Zrinzo L, Foltynie T, Limousin P: Improvement of tics after subthalamic nucleus deep brain stimulation. Neurology 2009;72:1787-1789. 